\title{
PARTISIPASI MASYARAKAT DALAM MEMBANGUN PENDIDIKAN NONFORMAL DI DUSUN SAMAN II, BANGUNHARJO, SEWON, BANTUL
}

\section{COMMUNITY PARTICIPATION IN BUILDING NONFORMAL EDUCATION IN SAMAN II VILLAGE, BANGUNHARJO, SEWON, BANTUL}

Oleh: Tri Astuti, Pendidikan Luar Sekolah

Triastuti056@gmail.com

\begin{abstract}
Abstrak
Penelitian ini bertujuan untuk mengungkapkan: (1) Partisipasi masyarakat (2) faktor penghambat partisipasi masyarakat dalam pembangunan pendidikan nonformal. Penelitian kualitatif dengan jenis studi kasus. Hasil penelitian partisipasi masyarakat terdiri dari (1) Motivasi partispasi masyarakat terdiri dari motivasi intrinksik dan motivasi ektrinsik, (2) bentuk-bentuk partisipasi terbagi dalam dua bentuk meliputi: (a) partisipasi fisik yaitu keahlian/ penyampaian ilmu pengetahuan, tempat, tenaga, pendanaan dan (b) partisipasi nonfisik yang terdiri dari pengawasan, motivasi, dan penyampaian ide pemikiran. Faktor penghambat partisipasi masyarakat yaitu (a) faktor malas, (b) faktor pekerjaan, (c) faktor pengurus internal, (d) faktor pengurus dusun, dan (e) faktor dana
\end{abstract}

Kata kunci: Partisipasi masyarakat, membangun, pendidikan nonformal

\begin{abstract}
The aim of research to determine: (1) Community participation, and (2) inhibiting factors of public participation in the development of non-formal education. Qualitative research with case study type. The results of the research community particiption are (1) The motivation of public participation are intrinsik motivation and extrinsik motivattion. The forms of participation fall into two forms: (a) physical participation, the skills / delivery of science, place, personnel, funding and (b) nonphysical participation consisting of supervision, motivation, and conveying ideas. (2) limiting factors of community participation are (a) lazy factors, (b) occupational factors, (c) internal management factors, (d) factor village administrator, and (e) fund factors
\end{abstract}

Keywords: Community Participation,building, nonformal education

\section{PENDAHULUAN}

Pendidikan merupakan hal terpenting dalam kehidupan manusia. Pendidikan merupakan kunci dalam pembentukan Sumber Daya Manuasia (SDM) yang berkualitas. Pendidikan juga bertujuan untuk mencerdaskan masyarakat agar masyarakat mampu hidup secara mandiri dan berdaya kehidupan Namun di Indonesia masih mengalami permasalahan dalam bidang pendidikan, seperti rendahnya tingkat pendidikan. Berdasarkan surat kabar harian Kompas pada tanggal 20 Oktober 2016 mengungkapkan bahwa terjadi masalah dalam pendidikan yaitu rendahnya tingkat pendidikan dari sebagian besar tenaga kerja di Indonesia, yaitu 42,9 persen dari masyarakat Indonesia hanya mampu mengenyam jenjang pendidikan tertinggi di tingkat Sekolah Dasar. Berdasarkan Ikhtisar Data Pendidikan tahun 2015/2016 yang dikeluarkan oleh Kementerian Pendidikan dan Kebudayaan yang dikutip dari Harian Kompas pada tanggal 10 Oktober 2016 menyatakan bahwa pada tahun 2015 terdapat 68.006 siswa yang putus sekolah di 


\section{Diklus: Jurnal Pendidikan Luar Sekolah, 1(2), September 2017 - 127 Tri Astuti}

Sekolah Dasar $(0,26$ persen dari total 25.885.053 peserta didik SD). Permasalahan putus sekolah juga mewarnai Kabupaten Gunungkidul, berdasarkan surat kabar Tribun Jogja pada hari Rabu Legi, 09 September 2015 menyebutkan bahwa pada tahun 2014 terdapat 291 kasus putus sekolah yaitu terdiri dari SD sebanyak 28, SMP ada 49 dan SMA sederajat mencapai 214.

Permasalahan pendidikan di Yogyakarta selain putus sekolah, yaitu kurang meratanya akses pendidikan di masing-masing kabupaten di Yogyakarta. Hal ini ditandai dengan kesenjangan IPM di masing-masing kabupaten. Berdasarkan data dari BPS menyebutkan IPM pada tahun 2015 di setiap kabupaten yaitu Kabupaten Gunung Kidul IPM 67,41, Kabupaten Kulon Progo IPM 71,52, Kabupaten Bantul 77,99, Kabupaten Sleman 81,20, dan Kota Jogja 84,56 (www.yogyakarta.bps.go.id). Perbedaan IPM tersebut disebabkan karena perbedaan pada tingkat harapan hidup, ratarata lama sekolah, angka melek huruf dan pendapatan per kapita.

Permasalahan pendidikan tersebut, dapat ditangani dengan perluasan dan pemerataan pendidikan melalui jalur pendidikan nonformal. Seperti yang tertuang dalam UU No. 20 Tahun 2003 Tentang Sisdiknas dalam pasal 13 yaitu jalur pendidikan terdiri atas pendidikan formal, nonformal dan informal yang dapat saling melengkapi dan memperkaya. Sehingga dengan adanya pendidikan nonformal dan informal maka akan dapat memperkaya dan melengkapi pendidikan yang telah diterima di pendidikan formal.

Faishal (1999:16) menyatakan bahwa pendidikan nonformal adalah beraneka warna bentuk kegiatan pendidikan yang terorganisasi atau setengah terorganisasi yang berlangsung diluar sistem persekolahan yang ditujukan untuk melayani sejumlah besar kebutuhan belajar dari berbagai kelompok penduduk, baik tua maupun muda. Pelaksanaan pendidikan nonformal dapat melalui lembaga-lembaga nonformal baik dari swasta maupun pemerintah seperti Taman Baca Masyarakat, PKBM, LKP, Rumah Pintar, majelis ta'lim, komunitas, Organisasi dan lembaga pendidikan masyarakat yang sejenis.

Tujuan pendidikan nonformal menururt Abdulhak (2012:44) yaitu bersifat multi purpose, yaitu ada tujuan pendidikan nonformal yang terfokus pada pemenuhan kebutuhan belajar dasar (basic education) semacam pendidikan keaksaraan, pengetahuan alam, ketrampilan vokasional, pengetahuan gizi serta kesehatan, sikap social dalam berkeluarga dll. Ada juga tujuan pendidikan nonformal yang ditujukan untuk kepentingan pendidikan kelanjutan setelah terpenuhinya pendidikan dasar, serta pendidikan perluasan dan pendidikan nilai- 


\section{Diklus: Jurnal Pendidikan Luar Sekolah, 1(2), September 2017 - 128 \\ Tri Astuti}

nilai hidup, misalnya pengajian, sekolah minggu, latihan kejiwaan meditasi, latihan pencarian makna hidup dll

Keberhasilan pendidikan nonformal di suatu negara membutuhkan kerjasama antara pemerintah, dan masyarakat. Pendidikan merupakan tanggung jawab bersama antara pemerintah dan masyarakat, tanpa ada dukungan masyarakat pendidikan tidak akan berhasil secara optimal sesuai apa yang diharapkan.

Partisipasi masyarakat merupakan peran masyarakat dalam memecahkan permasalahan di suatu masyarakat. Partisipasi memiliki arti yang sangat luas dan beragam. Partisipasi merupakan suatu wujud dari peran serta masyarakat dalam mencapai suatu tujuan bersama dalam suatu komunitas atau masyarakat. Wujud dari partisipasi tersebut dapat berupa kritik, saran, jasa atau dalam bentuk materi baik secara langsung maupun tidak langsung. Partisipasi masyarakat sangat penting dalam pembangunan pendidikan, seperti yang diungkapkan oleh Kamil (2009:202) menyatakan bahwa partisipasi masyarakat merupakan suatu hal terpenting dalam kegiatan-kegiatan pendidikan social, hal tersebut sejalan dengan karakteristik dan konsep pendidikan nonformal.

Sejalan dengan itu, peneliti menemukan salah satu dusun di Kabupaten Bantul, yaitu Dusun Saman II. Di dusun ini rentan sekali terjadi permasalahan social seperti pemuda yang mabuk-mabukan, tawuran, penggunaan narkoba dan lain-lain. Hal ini sesuai dengan hasil wawancara dengan saudara "La" selaku wakil Karang Taruna FKPS, yang menyatakan bahwa dusun Saman merupakan dusun yang sangat rawan sekali akan permasalahan social. Kasuskasus yang pernah terjadi yaitu penyalahgunaan narkoba, mabuk-mabukan, pergaulan bebas, dan penganiayaan (Wawancara Senin 23 Januari 2017). Selain itu Dusun saman merupakan lokasi yang strategis sehingga banyak pendatang yang mengkontrak rumah di Dusun Saman. Hal ini memicu terjadinya permasalahan, seperti kontrakan sebagai tempat pergaulan bebas dan tempat membuat kerisuhan. Seperti kasus penganiayaaan Siswi SMA di salah satu kos di Dusun Saman, Desa Bangunharjo, Kecamatan Sewon, Kabupaten Bantul pada hari Kamis 12 Desember 2015. Kasus ini terjadi karena tato Hello Kitty yang dititru oleh korban, sehingga pelaku penganiaya tidak rela apabila tato hello kitty itu ditiru oleh orang lain (news.detik.com).

Permasalahan sosial di Dusun Saman II diatasi melalui kegiatan-kegiatan kemasyarakatan atau program pendidikan nonformal yang dapat menambah wawasan masyarakat. Hal ini seperti yang disampaikan oleh saudara "La" selaku wakil Karang Taruna FKPS, yang menyatakan bahwa untuk menanangani permasalahan- 


\section{Diklus: Jurnal Pendidikan Luar Sekolah, 1(2), September 2017 - 129 \\ Tri Astuti}

permasalahan social tersebut, masyarakat membentuk wadah kegiatan masyarakat melalui kegiatan-kegiatan kerohanian, seperti pengajian, TPA dan lain-lan, (wawancara Senin 23 Januari 2017). Kegiatan-kegiatan pendidikan nonformal tersebut meliputi:(a) Program Pendidikan Anak Usia Dini (PAUD) Satuan Paud Sejenis (SPS), (b) Taman Pendidikan Al Qur'an (TPA) Pengajian Al Qur'an Al Audad Saman (PAAS), (c) Kegiatan Taman Baca Masyarakat (TBM) Gubuk Cakrawala, (d) Majelis Ta'lim Mushola As Shalimi, (e) Majelis Ta'lim Masjid Baiturrahman, (f) Hadroh As Samany dan (g) Forum Komunikasi Pecinta Saman (FKPS). Program-program kegiatan tersebut, apabila dilihat dalam pelaksanaan kegiatanya sudah terdapat kerjasama antar masyarakat dalam pembangunan program pendidikan nonformal. Agar mengetahui lebih jelas partisipasi masyarakat dalam setiap program pendidikan nonformal di dusun Saman, maka perlu adanya penelitian

Tujuan dari penelitian ini yaitu untuk menjelaskan tentang partisipasi masyarakat dan faktor penghambat partisipasi masyarakat dalam pembangunan pendidikan nonformal di dusun Saman II, Bangunharjo, Sewon, Bantul.

\section{METODE PENELITIAN}

\section{Jenis Penelitian}

Penelitian menggunakan pendekatan kualitatif jenis studi kasus bertujuan untuk menggambarkan partisipasi masyarakat dalam membangun pendidikan nonformal di Dusun Saman II. Dusun Saman secara menyeluruh, terperinci dan utuh

\section{Waktu dan Tempat Penelitian}

Waktu penelitian dilakukan pada bulan Januari sampai dengan bulan Mei 2017. Tempat penelitian yaitu di dusun Saman II, Bangunharjo, Sewon, Bantul.

\section{Target/Subjek Penelitian}

Subyek penelitiannya adalah partisipasi masyarakat, dengan informan pengurus program pendidikan nonformal, masyarakat sasaran dan pengurus dusun.

\section{Data, Intrumen, dan Teknik Pengumpulan Data}

Sumber data yaitu pengurus program pendidikan nonformal, masyarakat sasaran, dan pengurus dusun. Teknik pengumpulan data dilakukan dengan observasi, wawancara mendalam, dan dokumentasi terhadap kelengkapan arsip atau dokumen lembaga,instrument pengumpul data berasal dari peneliti sendiri, bertindak sebagai instrument kunci yang dapat mengembangkan instrument pedoman observasi, dokumentasi dan wawancara

\section{Teknik Analisis Data}

Teknis analisis data menggunakan teknik komponensial, dengan langkah analisis yaitu:

a. Reduksi data 


\section{Diklus: Jurnal Pendidikan Luar Sekolah, 1(2), September 2017 - 130 Tri Astuti}

Reduksi data merupakan proses merangkum, memilih data yang pokok atau inti, memfokuskan pada hal-hal yang penting. Hal ini agar memberikan gambaran yang jelas dari hasil penelitian

b. Display Data

Setelah data direduksi, maka langkah selanjutnya adalah mendisplay data. Penyajian data dapat dilakukan dalam bentuk uraian singkat, bagan, hubungan antar kategori

c. Penarikan Kesimpulan

Penarikan kesimpulan yaitu peneliti mencari makna dari data yang telah dikumpulkan kemudian menyusun pola hubungan tertentu ke dalam satu kesatuan informasi yang muadah ditafsirkan dan dipahami sesuai dengan masalahnya

\section{Keabsahan Data}

Pada penelitian ini peneliti menggunakan triangulasi sumber dan teknik, yaitu dengan melalukan pembandingan terhadap informan yang berbeda dan membandingkan dengan hasil observasi serta dokumentasi.

\section{HASIL PENELITIAN DAN PEMBAHASAN}

Hasil

Dusun Saman II, Bangunharjo, Sewon, Bantul merupakan daerah yang rawan akan permasalahan social, akan tetapi di dusun Saman II memiliki berbagai program pendidikan nonformal. Program tersebut yaitu (1) majelis ta'lim Mushola As Salimi, (2) majelis ta'lim Masjid Baiturrahman, (3) TPA PAAS Saman II, (4) TBM Gubuk Cakrawala, (5) PAUD SPS Idaman, (6) Karang Taruna FKPS, dan (7) Hadroh As Samany. Pada penelitian ini, meneliti tentang partisipasi masyarakat yang dilihat dari segi motivasi, bentuk dan faktor penghambat partisipasi masyarakat.

\section{Motivasi Partisipasi Masyarakat}

Motivasi partisipasi masyarakat berbedabeda setiap program pendidikan nonformal. Berikut motivasi partisipasi masyarakat:

\begin{tabular}{|c|c|}
\hline $\begin{array}{c}\text { Program } \\
\text { Pendidikan }\end{array}$ & Motivasi \\
\hline $\begin{array}{l}\text { Majelis } \\
\text { Ta'lim } \\
\text { Mushola As } \\
\text { Salimi }\end{array}$ & $\begin{array}{l}\text { 1. Membimbing masyarakat } \\
\text { menjadi lebih baik. } \\
\text { 2. Memperluas ilmu pengetahuan } \\
\text { Agama Islam, } \\
\text { 3. Menjalin Silaturahmi. }\end{array}$ \\
\hline $\begin{array}{l}\text { Majelis } \\
\text { Ta'lim } \\
\text { Masjid } \\
\text { Baiturrahman }\end{array}$ & $\begin{array}{l}\text { 1.Meningkatkan Ilmu } \\
\text { Pengetahuan Agama Islam, } \\
\text { 2.Mempererat silaturahmi }\end{array}$ \\
\hline $\begin{array}{l}\text { TBM Gubuk } \\
\text { Cakrawala }\end{array}$ & $\begin{array}{l}\text { 1.Mengembankan kemampuan } \\
\text { masyarakat } \\
\text { 2.Meningkatkan pengetahuan }\end{array}$ \\
\hline $\begin{array}{l}\text { TPA PAAS } \\
\text { Saman II }\end{array}$ & $\begin{array}{l}\text { 1. Meningkatkan derajat } \\
\text { pendidikan masyarakat, } \\
\text { 2.Meningkatkan pengetahuan, } \\
\text { 3.Mewadahi masyarakat untuk } \\
\text { menuntut ilmu }\end{array}$ \\
\hline $\begin{array}{l}\text { PAUD SPS } \\
\text { Idaman }\end{array}$ & $\begin{array}{l}\text { 1.Meningkatkan kemampuan } \\
\text { anak, } \\
\text { 2.Melatih jiwa sosial anak. }\end{array}$ \\
\hline $\begin{array}{l}\text { Karang } \\
\text { Taruna FKPS }\end{array}$ & $\begin{array}{l}\text { 1.Mengatasi hal-hal negative, } \\
\text { 2.Mengembangkan wawasan, } \\
\text { 3.Menjalin silaturahmi. }\end{array}$ \\
\hline $\begin{array}{l}\text { Hadroh As } \\
\text { Samany }\end{array}$ & $\begin{array}{l}\text { 1.Sebagai bentuk syiar agama } \\
\text { Islam } \\
\text { 2. Sebagai wadah kegiatan yang } \\
\text { positif }\end{array}$ \\
\hline
\end{tabular}




\section{Diklus: Jurnal Pendidikan Luar Sekolah, 1(2), September 2017 - 131 Tri Astuti}

Tabel 1. Motivasi Partisipasi Masyarakat

Motivasi partisipasi masyarakat dalam membangun pendidikan nonformal berbedabeda dalam setiap program pendidikan nonformal. Sebagian besar motivasi partisipasi masyarakat yaitu untuk untuk mengembangkan ilmu pengetahuan atau wawasan Agama Islam, menjalin silaturahmi,meningkatkan derajat pendidikan masyarakat, untuk beribadah dan upaya untuk menangani permasalahan social di Dusun Saman II, Bangunharjo, Sewon, Bantul.

\section{Bentuk-Bentuk Partisipasi Masyarakat}

Bentuk-bentuk partisipasi masyarakat dalam membangun pendidikan nonformal di Dusun Saman II, Bangunharjo, Sewon, Bantul terdiri dari partisipasi fisik dan partisipasi nonfisik.

\begin{tabular}{|l|l|l|}
\hline \multicolumn{1}{|c|}{$\begin{array}{c}\text { Program } \\
\text { Pendidikan }\end{array}$} & \multicolumn{2}{|c|}{ Bentuk Partisipasi } \\
\cline { 3 - 3 } Nonformal & Fisik & \multicolumn{1}{c|}{ Non-Fisik } \\
\hline Majelis & a. kehadiran & a.Pengawasan \\
Ta'lim & b.Pendanaan & b.Motivasi \\
Mushola As & c. Keahlian & c.penyampaian \\
Salimi & d. Tenaga & pendapat \\
\hline Majelis & a. kehadiran & a.Pengawasan \& \\
Ta'lim & b.Pendanaan & motivasi \\
Masjid & c. Tenaga & b.Penyampaian \\
Baiturrahma & d. Keahlian & pendapat \\
n & & \\
\hline TBM Gubuk & a.Pendanaan & Penyampaian \\
Cakrawala & b. Tempat & pendapat \\
& c. Ketrampilan & \\
\hline TPA PAAS & a. Keterlibatan & a. Penyampaian \\
Saman II & / kehadiran & pendapat \\
b.Pendanaan & b.Pengawasan \\
\hline
\end{tabular}

\begin{tabular}{|c|c|c|}
\hline & $\begin{array}{l}\text { c. Tempat } \\
\text { d.Tenaga } \\
\text { e. Keahlian }\end{array}$ & c. Motivasi \\
\hline $\begin{array}{l}\text { PAUD SPS } \\
\text { Idaman }\end{array}$ & $\begin{array}{l}\text { a. Kehadiran } \\
\text { b.Pendanaan } \\
\text { c. Tempat }\end{array}$ & $\begin{array}{l}\text { Penyampaian } \\
\text { pendapat }\end{array}$ \\
\hline $\begin{array}{l}\text { Karang } \\
\text { Taruna } \\
\text { FKPS }\end{array}$ & $\begin{array}{l}\text { a. Kehadiran } \\
\text { b.Pendanaan } \\
\text { c. Tenaga } \\
\text { d.Tempat } \\
\text { e. Keahlian }\end{array}$ & $\begin{array}{l}\text { Penyampaian } \\
\text { pendapat }\end{array}$ \\
\hline $\begin{array}{l}\text { Hadroh As } \\
\text { Samany }\end{array}$ & $\begin{array}{l}\text { a. Kehadiran } \\
\text { b. Keahlian } \\
\text { c. Pendanaan }\end{array}$ & $\begin{array}{l}\text { a. Pengawasan } \\
\text { b. Motivasi } \\
\text { c. Penyampaian } \\
\text { pemikiran }\end{array}$ \\
\hline
\end{tabular}

\section{Faktor Penghambat Partisipasi}

\section{Masyarakat}

Faktor penghambat partisipasi masyarakat yaitu (1) faktor pekerjaan, (2) faktor malas, (3) faktor pengurus internal, (4) faktor dana dan (5) faktor pengurus dusun.

\begin{tabular}{|c|c|}
\hline $\begin{array}{c}\text { Program } \\
\text { Pendidikan }\end{array}$ & Faktor Penghambat \\
\hline $\begin{array}{lr}\text { Majelis } & \text { Ta'lim } \\
\text { Mushola } & \text { As } \\
\text { Salimi } & \end{array}$ & Malas, pekerjaan masyarakat \\
\hline $\begin{array}{l}\text { Majelis Ta'lim } \\
\text { Masjid } \\
\text { Baiturrahman }\end{array}$ & $\begin{array}{l}\text { Malas, ekonomi rendah, } \\
\text { pekerjaan masyarakat, kurang } \\
\text { loyalnya pengurus Masjid } \\
\text { Baiturrahman }\end{array}$ \\
\hline $\begin{array}{l}\text { TBM Gubuk } \\
\text { Cakrawala }\end{array}$ & $\begin{array}{l}\text { Dana (belum memiliki dana } \\
\text { mandiri), pengurus TBM } \\
\text { tidak loyal, pekerjaan } \\
\text { masyarakat }\end{array}$ \\
\hline
\end{tabular}


Diklus: Jurnal Pendidikan Luar Sekolah, 1(2), September 2017 - 132

Tri Astuti

\begin{tabular}{|lr|l|}
\hline \multicolumn{2}{|l|}{ TPA PAAS II } & Malas, ekonomi, \\
\hline $\begin{array}{l}\text { PAUD SPS } \\
\text { Idaman }\end{array}$ & & $\begin{array}{l}\text { Malas, belum ada rapat antar } \\
\text { pengurus dan orangtua tua } \\
\text { siswa (komunikasi) }\end{array}$ \\
\hline $\begin{array}{l}\text { Karang } \\
\text { FKPS }\end{array}$ & Taruna & $\begin{array}{l}\text { Malas, kurang partisipasi } \\
\text { dalam berpendapat, kurang } \\
\text { dukungan dari pengurus } \\
\text { dusun. }\end{array}$ \\
\hline $\begin{array}{l}\text { Hadroh } \\
\text { Samany }\end{array}$ & As & $\begin{array}{l}\text { Belum memiliki dana } \\
\text { mandiri, kurangnya dukungan } \\
\text { dari pengurus masjid }\end{array}$ \\
\hline
\end{tabular}

\section{Pembahasan}

\section{Partisipasi Masyarakat}

Penelitian partisipasi masyarakat dalam membangun pendidikan nonformal di Dusun Saman II, Bangunharjo fokus pada motivasi partisipasi masyarakat dan bentuk-bentuk partisipasi masyarakat.

a.Motivasi Partisipasi Masyarakat

Motivasi partisipasi masyarakat dalam pembangunan pendidikan nonformal di Dusun Saman II terbagi menjadi dua yaitu partisipasi intrinsik dan ektrinsik. Motivasi intrinsik berasal dari dalam diri individu. Masyarakat termotivasi terlibat dalam kegiatan pendidikan nonformal karena kebutuhan masyarakat akan ilmu pengetahuan baik pengetahuan umum maupun pengetahuan agama Islam, kebutuhan kegiatan yang positif dan kebutuhan menjalin silaturahmi. Melalui ilmu pengetahuan tersebut, masyarakat berharap dapat mengembangkan wawasan atau kemampuannya dan dapat mengaplikasikan dalam kehidupan sehari-hari.
Melalui kegiatan pendidikan nonformal, maka masyarakat akan saling berkomunikasi, berjabat tangan, menanyakan kabar, maka hal ini akan mewujudkan keharmonisan dalam bermasyarakat. Masyarakat membangun pendidikan nonformal salah satu tujuannya yaitu untuk mewadahi masyarakat agar memiliki kegiatan yang positif, hal ini sebagai salah satu upaya untuk mencegah permasalahanpermasalahan social. Selain itu, masyarakat juga memiliki kemauan atau minat berpartisipasi dalam pembangunan pendidikan nonformal untuk membantu masyarakat dalam beribadah dan meningkatkan derajat pendidikan di dusun Saman, baik pendidikan formal maupun nonformal. Motivasi partisipasi masyarakat dalam pembangunan pendidikan nonformal ini sesuai dengan teori yang dikatakan oleh Anwar (2012: 147) bahwa motivasi intrinsik timbul dari setiap individu seperti kebutuhan, bakat, kemauan, minat dan harapan yang terdapat pada diri seseorang. Motivasi partisipasi masyarakat dusun Saman II juga sesuai dengan hasil penelitian Anwar terkait pengembangan model pengelolaan pembelajaran ketrampilan berbasis social budaya dan perempuan nelayan bahwa motivasi perempuan nelayan Suku Bajo ikut dalam kegiatan program pembangunan desanya karena merasa tertinggal dibandingkan dengan desa-desa tetangga, sehingga masyarakat ingin mewujudkan desanya lebih maju. Begitupula dengan masyarakat dusun Saman II, bahwa motivasi masyarakat dalam pembangunan pendidikan nonformal untuk meningkatkan derajat pendidikan masyarakat.

Motivasi ektrinsik merupakan motivasi dari luar individu. Masyarakat 


\section{Diklus: Jurnal Pendidikan Luar Sekolah, 1(2), September 2017 - 133 Tri Astuti}

termotivasi terlibat dalam kegiatan pendidikan nonformal karena dorongan dari luar, seperti adanya motivasi. Masyarakat terlibat dalam kegiatan pendidikan nonformal adanya motivasi dari pengurus dusun (kepala dusun, ketua RT, RW, seksi kerohanian, dan seksi pendidikan) agar masyarakat selalu mengikuti kegiatan pendidikan nonformal di dusun Saman. Bentuk motivasi ini berupa penyadaran. Motivasi bersifat penyadaran yaitu berupa ajakan kepada masyarakat. Ajakan ini disampaikan secara langsung atau melalui sambutan ketika ada kegiatan berlangsung. Hal ini sesuai dengan pendapat Anwar (2012:149) bahwa motivasi yang diberikan oleh tokoh-tokoh masyarakat dan sumber belajar adalah bersifat memberi harapan dan penyadaran. Pemberian harapan berupa dorongan dan rangsangan melalui pujian atau hadiran. Motivasi bersifat penyadaran yaitu berupa ajakan.

\section{b. Bentuk-Bentuk Partisipasi Masyarakat}

Menurut Basrowi dalam Dwiningrum (2015:58) membagi partisipasi menjadi dua bentuk yaitu partisipasi nonfisik dan partisipasi fisik. Partisipasi fisik adalah partisipasi masyarakat, dalam bentuk menyelenggarakan usaha-usaha pendidikan, seperti mendirikan dan menyelenggarakan usaha sekolah atau lembaga pendidikan. Partisipasi nonfisik yaitu keikutsertaan masyarakat dalam menyelenggarakan pendidikan yang tidak berwujud fisik.
Partisipasi fisik adalah partisipasi masyarakat yang wujud partisipasinya berupa fisik dan dapat dilihat secara fisik. Bentuk partisipasi fisik dalam pembangunan pendidikan nonformal di dusun Saman II yaitu terdiri dari partisipasi keterlibatan/ kehadiran, partisipasi pendanaan, partisipasi keahlian/ penyampaian ilmu pengetahuan, partisipasi tempat, dan partisipasi tenaga. Wujud dari partisipasi masyarakat tersebut berupa fisik dan dapat dilihat secara fisik, sehingga peneliti mengkategorikan partisipasi tersebut kedalam bentuk partisipasi fisik.

Partisipasi nonfisik adalah partisipasi masyarakat yang wujudnya tidak berupa fisik dan tidak dapat dilihat secara fisik. Menurut Dwiningrum (2015:58) menyatakanbahwa partisipasi nonfisik yaitu keikutsertaan masyarakat dalam menyelenggarakan pendidikan yang tidak berwujud fisik. Sejalan dengan teori tersebut, maka bentuk nonfisik partisipasi masyarakat dalam membangun pendidikan nonformal yaitu berupa partisipasi pengawasan, partisipasi motivasi dan partisipasi penyampaian ide pemikiran atau pendapat. Wujud dari partisipasi tersebut tidak dapat dilihat secara fisik, sehingga peneliti mengkategorikan dalam bentuk partisipasi nonfisik.

\section{c. Faktor-Faktor Penghambat}

Faktor-faktor penghambat partisipasi masyarakat yaitu:

1) Faktor Malas.

Menurut Dwiningrum (2015:57) faktor penghambat dalam partisipasi masyarakat yaitusifat malas, apatis, masa bodoh, tidakmau 


\section{Diklus: Jurnal Pendidikan Luar Sekolah, 1(2), September 2017 - 134 Tri Astuti}

melakukan perubahan di tingkat anggota masyarakat. Hal ini sejalan dengan hasil penelitian peneliti bahwa salah satu penghambat masyarakat dalam berpartisipasi membangun pendidikan nonformal yaitu malas. Malas timbul karena beberapa penyebab diantaranya yaitu karena capek setelah berkegiatan, masyaraka yang memiliki rasa masa bodoh terhadap kegiatan kemasyarakatan dan lain-lain. Apabila rasa malas timbul dalam diri masyarakat, maka penyebabkan penghambat masyarakat untuk hadir dalam kegiatan pendidikan nonformal.

\section{2) Faktor Pekerjaan}

Menurut Slamet dalam Hermawan dan Yoyon (2017:107) menyatakan bahwa jenis pekerjaan masyarakat akan memmpengaruhi dan menentukan tingkat partisipasi kaitannya dengan penghasilan dan terlebih pada waktu luang mereka untuk digunakan dalam berpartisipasi. Pekerjaan masyarakat dapat menghambat partisipasi masyarakat dalam kegiatan pendidikan nonformal. Biasanya waktu bekerja bersamaan dengan kegiatan yang ada di masyarakat, terlebih masyarakat yang bekerja pada malam hari, karena kegiatan pendidikan nonformal sebagian besar dilaksanakan malam hari.

\section{3) Pengurus Internal}

Pengurus dapat menjadikan penghambat partisipasi apabila pengurus suatu program pendidikan nonformal kurang loyal. Menururt Hiryanto (2005:70) salah satu penghambat partisipasi masyarakat dalam pengembangan PLS yaitu masih rendahnya loyalitas pengelola dalam merealisasikan program magang. Hal ini sejalan dengan hasil penelitian peneliti yaitu terdapat pengurus program pendidikan nonformal yang kurang loyal, sehingga pengurus tidak bisa menggandeng semua kalangan masyarakat di dusun Saman II. Hal ini menyebabkan masyarakat enggan untuk terlibat dalam kegiatan pendidikan nonformal tersebut.

\section{4) Faktor Pengurus Dusun}

Partisipasi dari pengurus dusun berupa dukungan baik materil maupun moril sangat penting dalam pembangunan pendidikan nonformal di masyarakat. Akan tetapi peneliti menemukan penghambat partisipasi masyarakat dalam pembangunan pendidikan nonformayal yaitu kurangnya dukungan dari pengurus dusun. Akibat dari kurangnya dukungan dari pengurus dusun yaitu lunturnya seemangat masyarakat dalam melaksanakan program pendidikan nonformal

\section{5) Faktor Dana}

Dana memiliki pengaruh dalam partisipasi masyarakat di dusun Saman II. Belum memiliki dana secara mandiri menjadi penghambat pengurus dalam melaksanakan kegiatan program pendidikan nonformal. Upaya untuk menangani kurangnya dana, maka pengurus berinisiatif melakukan iuran dan penggalangan dana. Selain dana dana dalam sebuah organisasi pendidikan nonformal, yang menjadi penyebab terhambatnya partisipasi masyarakat yaitu rendahnya pendapatan masyarakat. Sehingga masyarakat terhambat dalam pembayaran biaya TPA dan merasa berat apabila masyarakat ditarik iuran berupa uang.

\section{SIMPULAN DAN SARAN}

Simpulan 


\section{Diklus: Jurnal Pendidikan Luar Sekolah, 1(2), September 2017 - 135 Tri Astuti}

Berdasarkan hasil penelitian dan pembahasan maka dapat disimpulkan bahwa partisipasi masyarakat sudah terlaksana dengan baik, hal ini dilihat dari beberapa aspek yaitu motivasi partisipasi masyarakat, dan bentukbentuk partisipasi masyarakat. Motivasi partisipasi masyarakat dalam membangun pendidikan nonformal yaitu motivasi intrinsik dan ektrinsik. Bentuk partisipasi terdiri dari partisipasi fisik dan partisipasi nonfisik. Partisipasi fisik terdiri dari (1) partisipasi pendanaan, (2) partisipasi tempat, 3) partisipasi keahlian/ penyampaian ilmu pengetahun, (4) partisipasi keterlibatan/ kehadiran dan (5) partisipasi tenaga. Sedangkan bentuk partisipasi nonfisik yaitu terdiri dari (a) partisipasi penyampaian ide pemikira/ pendapat, (b) partisipasi motivasi, (c) partisipasi pengawasan.

Faktor penghambat partisipasi masyarakat dalam membangun pendidikan nonformal yaitu (1) faktor malas, (2) faktor pekerjaan, (3) faktor pengurus program pendidikan non formal, (4) faktor pengurus dusun dan (5) faktor dana

\section{Saran}

1. Pengurus dusun harus lebih memperhatikan dan memberdayakan program pendidikan nonformal, agar program pendidikan nonformal yang ada tetap berjalan dengan baik.

2. Pemerintah Desa ataupun instansi terkait dapat memberikan bantuan berupa pendanaan kegiatan dan penyediaan tenaga ahli, sehingga dapat menyalurkan ilmu pengetahuannya kepada masyarakat.
3. Masyarakat diharapkan mampu memanfaatkan program pendidikan nonformal yang sudah ada untuk meningkatkan kemampuan dirinya.

\section{DAFTAR PUSTAKA}

Amirin, M Tatang. (2013). Manajemen Pendidikan. Yogyakarta: UNY Press

BPS.(2015). diakes melalui Yogyakarta.bps.go.id pada hari Selasa 15 November 2016 pukul 19.30 WIB

Dwiningrum, S.I.A. (2015). Desentralisasi dan Partisipasi Masyarakat dalam Pendidikan. Yogyakarta: Pustaka Pelajar Offset

Hermawan, Yudan \& Yoyon, Suryono,. (2016). Partisipasi Masyarakat Dalam Penyelenggaraan ProgramProgram Pusat Kegiatan Belajar Masyarakat Ngudi Kapinteran. Jurnal Pendiidkan dan Pemberdayaan Masyarakat. 3 (1), 97-108

Hiryanto. (2005). Partisipasi Masyarakat dalamvPengembangana PLS Melalui Pusat Kegiatan Belajar Masyarakat (PKBM) di Kota Yogyakarta. Jurnal Diklus Edisi 5, 56-72

Kamil, Mustofa. (2012). Model Pendidikan

dan Pelatihan (Konsep dan Aplikasi). Bandung: Alfabeta Bandung.

Sudirman. (2011). Partisipasi Tokoh Masyarakat dalam Pembangunan Desa (Studi di Desa Unteboang Kecamatan Sosorgadong Kabupaten Tapanuli Tengah Provinsi Sumatera Utara. Jurnal Pendidikan Luar 
Diklus: Jurnal Pendidikan Luar Sekolah, 1(2), September 2017 - 136

Tri Astuti

Sekolah UPI Volume 7, Nomor 1 Tahun 2011.

Undang-Undang RI No. 20 Tahun Pendidikan.(2003). Undang-Undang
RI No.20 Tahun 2003 Tentang Sistem Pendidikan Nasional.

Bandung: Citra Umbara 